\title{
Research review: Goals, intentions and mental states: challenges for theories of autism
}

\author{
Antonia F. de C. Hamilton \\ School of Psychology, University of Nottingham, UK
}

\begin{abstract}
The ability to understand the goals and intentions behind other people's actions is central to many social interactions. Given the profound social difficulties seen in autism, we might expect goal understanding to be impaired in these individuals. Two influential theories, the 'broken mirror' theory and the mentalising theory, can both predict this result. However, a review of the current data provides little empirical support for goal understanding difficulties; several studies demonstrate normal performance by autistic children on tasks requiring the understanding of goals or intentions. I suggest that this conclusion forces us to reject the basic broken mirror theory and to re-evaluate the breadth of the mentalising theory. More subtle theories which distinguish between different types of mirroring and different types of mentalising may be able to account for the present data, and further research is required to test and refine these theories. Keywords: Autistic disorder, brain imaging, cognition, theory of mind.
\end{abstract}

Every day, we see other people move through the world, taking objects from one location to another. From this complex visual array, we can effortlessly make inferences about goals and mental states - she wants to buy an apple; he is trying to find and answer his mobile phone; she likes coffee. One group of individuals, those with autism, can see the same scene but might not make the same inferences. Two current theories of autism, the 'broken mirror' theory (Iacoboni \& Dapretto, 2006; Ramachandran \& Oberman, 2006; Williams, Whiten, Suddendorf, \& Perrett, 2001) and the 'mentalising theory' (Frith, Morton, \& Leslie, 1991), predict that individuals with autistic spectrum disorders (ASD) may have difficulty understanding the goals and intentions behind other people's actions. The current paper aims to examine these predictions and assess the evidence for goal understanding in autism. Reviewing a series of studies which use a variety of paradigms, there is emerging evidence that individuals with autism can infer many of the goals and intentions behind another person's action, just like typical individuals. These initial results present a serious problem for the broken mirror theory, and may also have interesting implications for our ideas about mentalising. However, exploring these theories also highlights the gaps in our current knowledge and reveals the scope for future research into goals and intentions in autism.

\section{Mentalising and broken mirrors}

I will begin with a brief overview of the origins of and strongest evidence for the mentalising hypothesis and the broken mirror hypothesis, highlighting both similarities and differences between them. The mentalising account of autism, also known as the 'theory of mind' account, is based on the finding that children with autism have specific difficulties with false belief tasks

Conflict of interest statement: No conflicts declared.
(Baron-Cohen, Leslie, \& Frith, 1985) and with pretend play (Wing, Gould, Yeates, \& Brierley, 1977). It is proposed that these difficulties are symptoms of an inability to represent other people's mental states (Frith et al., 1991), or to decouple mental states from reality (Leslie, 1987). There is no consensus on precisely what counts as a mental state; beliefs, desires, goals, emotions and perceptions are all frequently suggested (Frith et al., 1991; Premack \& Woodruff, 1978; Saxe, Carey, \& Kanwisher, 2004), so the current paper will take a broad view of mentalising and consider all of these as mental states. As mental state representations are fundamental to many social and communicative interactions, a specific cognitive deficit in representing mental states could give rise to a much broader array of behavioural difficulties in the social domain. For example, an understanding of other people's beliefs and the concept that beliefs differ between individuals is fundamental to much of human communication - a child who does not realise that his mother is ignorant of his desires has no motivation to ask for what he wants (Frith, 2003). Thus, an inability to represent abstract mental states would impact on simpler social behaviours.

In contrast, the broken mirror theory of autism focuses initially on low-level mechanisms of social behaviours such as the recognition of actions and emotions. The theory is based on the discovery of mirror neurons in the macaque monkey which respond to the actions of self and other (di Pellegrino, Fadiga, Fogassi, Gallese, \& Rizzolatti, 1992), and on the neuroimaging evidence for an equivalent mirror neuron system in the human brain (Rizzolatti \& Craighero, 2004). The human mirror neuron system (MNS) seems to allow people to match their own behaviour to that of others, and has thus been hailed as a unifying basis for social cognition (Gallese, Keysers, \& Rizzolatti, 2004). For example, the human MNS is involved in imitation (Buccino et al., 2004; Decety, Chaminade, Grezes, \& Meltzoff, 2002; Iacoboni et al., 1999) and mirroring has also been 
implicated in emotional contagion (Singer et al., 2004; Wicker et al., 2003). Some suggest that these processes may provide a fundamental step towards language (Rizzolatti \& Arbib, 1998), empathy (Gallese, 2003) and even mentalising (Gallese \& Goldman, 1998) abilities. However, the evidence for some of these claims remains weak.

The key link between the MNS and autism comes from studies of imitation behaviour. When typical adults imitate hand actions, the MNS is activated (Buccino et al., 2004; Decety et al., 2002; Iacoboni et al., 1999) and damage to the MNS in adults causes imitation difficulties (Heilman, Rothi, \& Valenstein, 1982). Children with autism may also have trouble with imitation tasks, as summarised in a recent meta-analysis (Williams, Whiten, \& Singh, 2004). Some studies report abnormal brain responses in autistic children during imitation (Dapretto et al., 2006) and action observation (Nishitani, Avikainen, \& Hari, 2004; Oberman et al., 2005). Based on these findings, it was suggested that dysfunction of the MNS in children with autism might cause first a lack of imitation, and later difficulties in understanding other people's intentions or emotions in social situations (Iacoboni \& Dapretto, 2006; Ramachandran \& Oberman, 2006; Williams et al., 2001). Thus, the broken mirror theory suggests that low-level problems with imitation and with matching the actions of self and other are the primary cause of difficulties with mentalising and more complex social interactions.

Contrasting these two theories, some important differences emerge. The traditional mentalising theory derives from a symbolic, abstract view of cognition (Leslie, 1987), while the broken mirror account is associated with an embodied approach which emphasises the role of simulation in understanding others (Gallese, 2003; Goldman, 2006). Similarly, the mentalising theory places the primary deficit in 'high level' reasoning about and representation of mental states, and assumes that abnormal social behaviour in simple situations is a consequence of this. Meanwhile, the broken mirror theory focuses on lower-level problems with imitation and assumes that failure on theory of mind tasks arises because simpler simulation mechanisms are dysfunctional in autism. Neither theory attempts to account for all the characteristics of autism, including nonsocial problems such as repetitive behaviours or differences in perceptual processing that might be attributed to weak central coherence (Frith \& Happé, 1994).

To test and discriminate between the mentalising theory and the broken mirror theory, it is interesting to examine the realms where they overlap. In particular, goals and intentions are relevant to both theories. Mirror neurons in macaque monkeys respond only to goal-directed actions (Fogassi et al., 2005; Gallese, Fadiga, Fogassi, \& Rizzolatti, 1996; Umilta et al., 2001), so goals are key to the original idea of mirror neuron function. The human MNS seems to be more general, with some response even to actions without a goal, but goal-directed actions are a powerful stimulus which robustly activate this system (Gazzola, Rizzolatti, Wicker, \& Keysers, 2007; Iacoboni et al., 2005; Koski et al., 2002). Damage to the human MNS, for example from stroke, is known to cause difficulties with understanding and performing meaningful or goal-directed actions (Buxbaum, Kyle, \& Menon, 2005). Therefore, lack of goal understanding in autism is a key prediction of the broken mirror theory.

Goals may also be considered as mental states, and comprehension of goals may require a degree of mentalising, at least under a broad mentalising theory. For example, the studies which spawned the field of 'Theory of Mind' examined how apes understand other people's intentional actions (Premack \& Woodruff, 1978). Thus, the question 'do individuals with autism understand goals?' has implications for both the broken mirror theory and the mentalising theory. The present paper examines what it means to understand a goal, whether this ability is lacking in autism, and the implications of goal understanding for our theories of autism.

\section{How do people understand goals and intentions?}

There is not yet a consensus on how typical individuals understand other people's goals and intentions, and there is even disagreement over what these terms mean. For example, many authors see intentions as complex mental states unique to the human (e.g. Blakemore \& Decety, 2001), while others apply this term to action sequences as represented in the macaque brain (Fogassi et al., 2005). Similarly, the distinction between goal and intention is seldom clear. This paper does not claim to resolve this controversy, and I use the terms goal and intention almost interchangeably.

There are currently two major competing models for how we understand other people's goals. The simulation model, most strongly associated with the mirror neuron system, proposes a process of 'direct matching' or 'resonance' which maps observed actions onto the observer's own motor system (Rizzolatti, Fogassi, $\&$ Gallese, 2001). It is argued that this direct matching process allows the observer to comprehend the actor's goal and maybe even other mental states by simulation (Gallese \& Goldman, 1998; Gallese et al., 2004). Similarly, the shared circuits model suggests that cognitive systems for motor control contribute to action simulation, mirroring and goal understanding (Hurley, 2008). The broken mirror theory of autism contends that this simulation mechanism, implemented in the mirror neuron system, is dysfunctional in autism.

In contrast, the inferential model (Csibra, 2007) proposes that observed actions must be parsed and interpreted using visual and inferential mechanisms before they can be understood or imitated. Recent fMRI results suggest that this inferential process involves the posterior superior temporal sulcus and temporoparietal junction (Brass, Schmitt, Spengler, \& Gergely, 2007; de Lange, Spronk, Willems, Toni, \& Bekkering, 2008), brain regions typically associated with mentalising (Frith \& Frith, 2003), not mirroring. Thus, inferential goal understanding may be closely related to mentalising. 
Under this model, activation of mirror neuron regions during action observation reflects a process of emulation which reconstructs the action after the primary comprehension process. Other models also exist. Some of these combine features of both the simulation model and the inferential model (Hamilton, 2008). Others take a computational approach and attempt to link different information processing steps to particular brain regions (Oztop, Kawato, \& Arbib, 2006). These models will not be considered in detail here.

A further important distinction in models on goal and intention understanding is between different levels of action representation. Actions or action sequences can be described at the level of complex goals (make an apple pie), simple goals (take apple, cut apple ...) or hand kinematics (reach, grasp, lift ...). Several different theoretical treatments of goal processing have suggested that goals are structured in a hierarchical fashion with complex goals having many simpler sub-goals (Bernstein, 1996; Fuster, 2001; Shallice \& Burgess, 1991). Behavioural evidence shows that action errors most often occur at the boundaries of the hierarchy (Reason, 1990). Furthermore, children imitate actions in a goal-directed fashion (Bekkering, Wohlschlager, \& Gattis, 2000) and according to a hierarchical structure (Whiten, Flynn, Brown, \& Lee, 2006). Neuroimaging results are now emerging to support the idea of a hierarchical organisation of goals and actions in the human brain (Grafton \& Hamilton, 2007; Hamilton \& Grafton, 2007; Koechlin \& Jubault, 2006; Koechlin, Ody, \& Kouneiher, 2003).

Figure 1 provides a sketch of this type of hierarchical organisation, showing how there are many different goals at different levels of complexity, from simply taking an object to a more complex sequence such as having breakfast. In this sketch, simple goals, complex goals and desires can all be seen as different levels of the same system, which implies a continuum from mental states such as desire to simple goals. A central question is whether simple goals, such as wanting an apple, should be considered as full-blown mental states and examined in relation to mentalising. While early studies took this approach (Premack \& Woodruff, 1978), some might argue for a clear distinction between mentalising processes and more basic goal understanding. Under such an account, only belief-desire reasoning would be classified as mentalising, with the implementation of goals and intentions left to other systems. The present paper takes a different approach, and explores the possibility that goals and intentions are a continuum with desires, beliefs and other mental states. This is a 'broad mentalising theory', and the overall value of such a theory will be assessed in the final section.

Research on goal understanding in autism has not yet explicitly tested inferential goal understanding compared to goal understanding by simulation. Similarly, few studies attempt to separate different levels of the goal hierarchy. In fact, many reports do not even distinguish between an understanding of a goal (as an internal state) and the understanding of the visible outcome of the goal-directed action. In the following

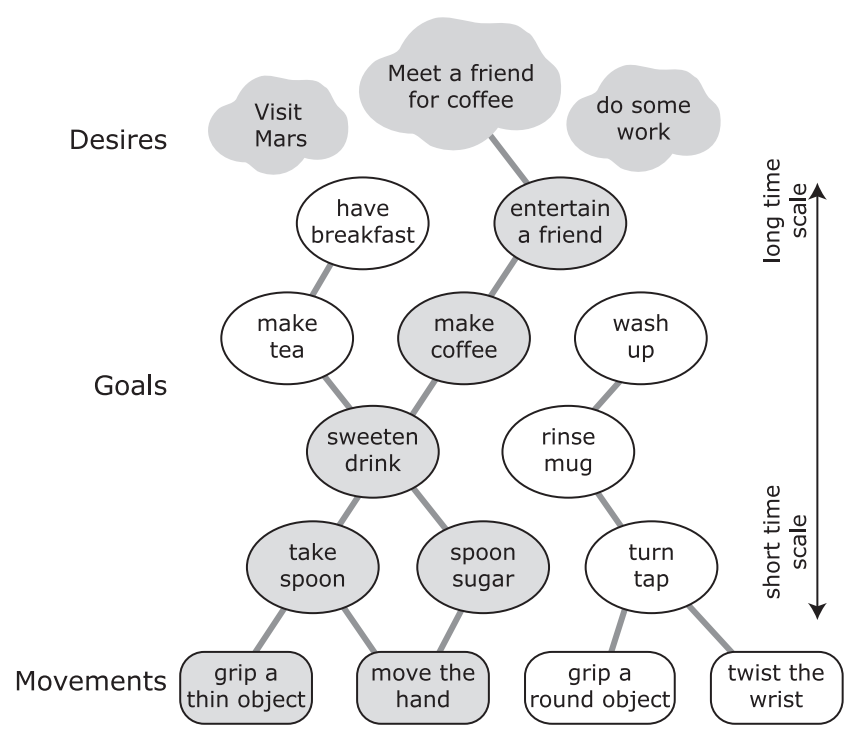

Figure 1 Schematic of the goal hierarchy. Desires are shown at the top of the hierarchy. When a goal crystallises into a plan for a goal-directed action, a series of goals and sub-goals at many levels of complexity are engaged (grey ovals). This set of goals can together be considered as an intention. The lowest level shown here is the level of basic movements; even simpler representations of muscle activity are not shown

discussion, I will attempt to distinguish if an experiment tests understanding of goals, intentions, outcomes or desires, regardless of the terminology used by the original authors.

\section{Do people with autism understand goals?}

There are not many direct tests of whether individuals with autism understand action goals. However, information can be gleaned from studies of imitation, and I also review the smaller number of goal understanding studies below.

\section{Imitation of goals}

Multiple studies have reported poorer imitation performance in children with autism compared to typical children on general batteries of imitation tasks (for example, Bernier, Dawson, Webb, \& Murias, 2007; DeMeyer et al., 1972; Ohta, 1987; Stone, Lemanek, Fishel, Fernandez, \& Altemeier, 1990). In particular, children with autism have difficulty with meaningless imitation tasks (Rogers, Bennetto, McEvoy, \& Pennington, 1996; Stone, Ousley, \& Littleford, 1997), mimicry of facial expressions (McIntosh, ReichmannDecker, Winkielman, \& Wilbarger, 2006) and with the spatial-perspective-taking component of an imitation task (Ohta, 1987; Smith \& Byrson, 1998). These results have led to the claim that there is a global imitation impairment in autism (Williams et al., 2004).

In the present context, the critical question is - does this global imitation impairment include difficulties with imitating the goal of an action? A study of very 
young children with autism (10 children, 20 months old) using a task requiring imitation of novel actions on objects found poor performance in the autism group (Charman et al., 1997). Several papers have reported impairments in imitation of object-directed or meaningful actions in children with autism (Bernier et al., 2007; DeMeyer et al., 1972; Rogers, Hepburn, Stackhouse, \& Wehner, 2003; Stone et al., 1990; Vivanti, Nadig, Ozonoff, \& Rogers, 2008). However, two key points should be noted. First, autistic children's performance on goal imitation, while poor, was often superior to their performance on imitation of meaningless actions (Vivanti et al., 2008). Second, a key limitation is that these studies mixed meaningful and meaningless imitation tasks in the same block. Work with adults suggests that such stimulus sets are treated as all meaningless (Tessari \& Rumiati, 2004). It is not yet known if children with autism fail imitation tasks with mixed blocks because they also treat all the stimuli as if they were meaningless or not goal directed. Some studies have reported impairment in goal-directed imitation in autism, but performance on goal-directed imitation was still better than performance on imitation of meaningless actions. Overall, these data suggest that imitation performance by children with autism is generally poor and this can include imitation of goals.

However, there are other reports of surprisingly good imitation of actions with a clear goal by individuals with autism. Children with autism imitate object-use actions (Beadle-Brown, 2004; Beadle-Brown \& Whiten, 2004; Charman \& Baron-Cohen, 1994; Morgan, Cutrer, Coplin, \& Rodrigue, 1989; Stone et al., 1997), while autistic adolescents show good imitation of meaningful actions (Rogers et al., 1996). Similarly, a study which tested delayed imitation on objects in six children with autism in a highly structured setting reported no differences between groups (McDonough, Stahmer, Schreibman, \& Thompson, 1997). Autistic children's imitation behaviour also seems to be directed towards a goal, with more imitation in cases where the action had a clear and interesting outcome (a light or sound) compared to cases without an outcome (Ingersoll, Schreibman, \& Tran, 2003).

Task instructions or context is a critical factor in imitation tasks and may particularly impact on the performance of autistic children. Autistic children successfully imitate when explicitly instructed to do so, whether imitating hand actions (Beadle-Brown \& Whiten, 2004) or facial expressions (McIntosh et al., 2006). They also show better performance in a highly structured imitation task than in a task requiring spontaneous imitation (Hepburn \& Stone, 2006). In a recent study, children with autism successfully imitated goal-directed actions, though they failed to integrate verbal cues with the observed action information to select which action to imitate (D'Entremont \& Yazbek, 2006). This result hints at problems with understanding all the cues which signal a person's intention, but not with understanding the action or its outcome. These data suggest that children with autism can imitate at least the outcome of another person's action, and may have some understanding of the underlying goal.

An interesting comparison in imitation studies is between imitation of a goal and imitation of kinematic features or action style, because these fall at different levels of the action hierarchy. Hobson and colleagues (Hobson \& Hobson, 2008; Hobson \& Lee, 1999) tested children with autism on a novel action imitation task. For example, children were shown how to scrape two objects together to make a sound and were asked to copy. Children with autism were able to perform the same, goal-directed action, but failed to mimic the style (loud or soft) with which the action was performed. Other studies have reported mixed results in imitation of action style, with one report of a failure to mimic kinematics (Becchio, Pierno, Mari, Lusher, \& Castiello, 2007) and one report of normal interference effects from observed actions (Gowen, Stanley, \& Miall, 2007). Evidence shows that adults with autism have normal automatic imitation of simple hand actions (Bird, Leighton, Press, \& Heyes, 2007).

A more direct test of goal understanding in autism can be found in studies which explicitly examined different levels of goal representation, based on work from Bekkering and colleagues. They showed that when typical 3-6-year-olds are asked to copy an adult's hand movement to a dot on the table, they accurately imitate the goal of the adult's action but do not necessarily use the same hand (Bekkering et al., 2000; Gattis, Bekkering, \& Wohlschlaeger, 2002). Bekkering and colleagues argue that this behaviour provides evidence for hierarchical goal representations in typical children, with the goal of the action (touch the dot) taking precedence over the means by which the action is performed (left or right hand) (Wohlschlager, Gattis, \& Bekkering, 2003).

Avikainen and colleagues tested 8 adults with Asperger's syndrome and 16 typical adults on a more complex version of this task. They found that typical adults showed a mirror advantage, in that they made fewer hand and grip errors when imitating as if looking in a mirror. In contrast, adults with Asperger's syndrome made the same number of hand and grip errors for mirror imitation and for anatomical imitation. Both groups made very few errors in imitating the goal of action and did not differ on this measure (Avikainen, Wohlschlager, Liuhanen, Hanninen, \& Hari, 2003). A replication of this study found poorer overall performance by 16 participants with autism (not just in the mirror imitation condition), and found similarly poor performance by the autistic participants when the task was instructed symbolically or when participants responded verbally (Leighton, Bird, Charman, \& Heyes, 2008). In both groups, the number of goal errors was low and did not differ between groups. The authors concluded that poor imitation performance in the autistic group in this task did not derive from a dysfunction of the mirror neuron system. For present purposes, the key point is that neither Avikainen and colleagues nor Leighton and colleagues found evidence that participants with autism had trouble imitating goals. 
Further evidence for good goal imitation can be found in a study which aimed to test the broken mirror theory (Hamilton, Brindley, \& Frith, 2007). Autistic children and controls matched for VMA were tested on Bekkering's goal-directed imitation task, and accurate goal imitation was found in both groups. More importantly, both typical and autistic children made systematic hand errors; when the demonstrator moved her hand across her body, the child correctly imitated the goal but failed to use the appropriate hand (Hamilton et al., 2007). This is the pattern of behaviour taken by Bekkering and colleagues to be a signature of goal-directed imitation. Children with autism are not imitating only the outcome of the action, but must be identifying the goal and selecting how to achieve that goal. Thus, the data provides evidence that both typical and autistic children have a goal hierarchy and can understand and imitate the goal of an adult's action.

There is also data showing that children with autism can and do go beyond the immediately visible goal of an adult's action, and are able to infer and imitate goals which they had not seen achieved. This is typically tested using a task where the child sees an adult attempt an action such as pulling apart a dumb-bell, but the adult's hand slips and the action is never completed (Meltzoff, 1995). Two independent studies (Aldridge, Stone, Sweeney, \& Bower, 2000; Carpenter, Pennington, \& Rogers, 2001) found that children with autism completed the action of pulling apart the dumb-bell, demonstrating their ability to understand the adult's goal from an incomplete demonstration. The results of these studies are particularly relevant to the mentalising theory, because to succeed on the task, the child must make goal inferences beyond the observed events. As a caveat, the study by Carpenter et al. did not find significant differences in behaviour after observing an incomplete goal-directed action compared to seeing the end state after the action was performed behind the experimenter's back. It is not clear if lack of a difference arises because children are imitating the end-state of the action or because they treat the hidden action as goal directed too. Further studies will be needed to clarify this point.

To summarise, there are some reports of failures on goal or object imitation tasks in autism but also a substantial number of reports of success. This inconsistency is likely due to the varied tasks and protocols used to assess imitation, with some studies mixing blocks of goal-directed and meaningless actions, while others keep them separate. The heterogeneity of the autistic population and the variety of ages and ability levels of the children tested may also contribute to variability. Failure on some tasks could be due to factors such as failure to comprehend instructions or the use of mixed task blocks which are not specific to goal understanding, whereas success by children with autism provides clear evidence for good goal understanding. Overall, there seems to be a consensus that children with autism perform better on tests of goal- or object-directed imitation than on tests of imitation of meaningless actions. More importantly, there are many circumstances in which children and adults with aut- ism can successfully imitate goals, including cases where the final outcome of the action is not seen.

\section{Understanding of other's goals}

The literature reviewed above focused on imitation tasks and seldom explicitly tested for comprehension of a goal. In many basic imitation tasks, a child can succeed by producing the same outcome as the demonstrator, without necessarily understanding the goal. However, a few studies can distinguish goals from outcomes. In some cases, evidence of goal understanding was found because both typical and autistic children made a systematic error as described above (Hamilton et al., 2007). In others, children went beyond the demonstration of a failed action and imitated the unseen goal (Aldridge et al., 2000; Carpenter et al., 2001). These results suggest that a child with autism can understand the goal of an adult's action and make his or her own goal equivalent to the adult's.

Further evidence for good goal understanding can be found in non-imitative tasks. For example, we recently compared the performance of typical and autistic children who were asked to recognise simple, meaningful actions using a task developed for patients with apraxia (Mozaz et al., 2006). Apraxia typically occurs after damage to the inferior parietal lobule or inferior frontal gyrus (the MNS regions of the human brain) and results in poor understanding, performance and imitation of actions (Buxbaum et al., 2005; Heilman et al., 1982). The nonverbal gesture recognition task developed by Mozaz and colleagues provides a good test of the ability to understand the goal or meaning of everyday actions. Surprisingly, the autistic group performed better than the typical controls on action recognition (Hamilton et al., 2007), providing further evidence against any specific difficulties with goal understanding in autism. Other researchers have also found good action recognition abilities in autism, using a gesture memory task (Rogers et al., 1996).

Understanding of more complex goals or action sequences has seldom been studied in autism and results are contradictory. One study using a picture ordering task to compare understanding of mental state sequences to simpler goal-directed action sequences found that individuals with autism had no problems understanding and ordering the goal-directed sequences (Baron-Cohen, Leslie, \& Frith, 1986). More recently, a similar study found that participants with autism did have trouble understanding object-directed action sequences (Zalla, Labruyere, \& Georgieff, 2006) but surprisingly not interactive action sequences. Further research will be needed to resolve these discrepancies.

Finally, a clever behavioural task demonstrated that adults with autism, like typical adults, represent their partner's goal and action. Sebanz and colleagues found that when a simple go/no-go reaction time task was arranged so that two people performed the task side by side, each responding to half the stimuli, an interference effect emerged as if one person were performing both halves of the task (Sebanz, Knoblich, \& Prinz, 
2003). This means that each participant represented the other's task as if it were his own. The same effect was found in participants with high-functioning autism (Sebanz, Knoblich, Stumpf, \& Prinz, 2005), meaning that these individuals also represent their partner's task and goal, even when it interferes with their own performance.

An important caveat to these goal-understanding studies is that none of them are formally equivalent to the false-belief task which is the quintessential test of mentalising ability. In the traditional false-belief task (Wimmer \& Perner, 1983), the child must be able to infer the actor's belief even though his or her own belief is different. A precisely equivalent test for goals is not easy to devise, but one study has tested autistic children's understanding of diverse desires. In the this task, the child is told that a doll likes a snack which the child dislikes, and must then predict which snack the doll will choose to eat (Wellman \& Liu, 2004). Recent data shows good performance in this task from autistic children, despite poor performance on traditional falsebelief tasks (Peterson, Wellman, \& Liu, 2005). Together, all these data indicate that children and adults with autism have good goal-understanding abilities, at least for the mainly simple goals which have been tested so far.

\section{Neuroimaging studies of imitation and goal understanding in autism}

Brain imaging methods provide an alternative source of information about how children with autism perceive, understand and imitate goals. Electroencephalogram (EEG) and magneto-encephalography (MEG) research has shown abnormal brain responses in children and adults with autism when observing another person's action (Bernier et al., 2007; Nishitani et al., 2004; Oberman et al., 2005). Similarly, motor-evoked potentials recorded in response to transcranial magnetic stimulation during the observation of a simple fingermoving action are reduced in participants with ASD compared to controls (Theoret et al., 2005). In contrast, magneto-encephalographic recordings from the brains of adults with autism and typical adults as they watched goal-directed actions failed to detect any group differences, though the number of participants was low (Avikainen, Kulomaki, \& Hari, 1999). Electromyographic recordings from facial muscles showed that children with autism failed to show anticipatory activation of jaw muscles when watching someone grasp a piece of food and prepare to eat (Cattaneo et al., 2007). Though there is good reason to suspect the involvement of the MNS in these tasks in the typical brain, these methods do not have the spatial resolution to precisely map the abnormalities observed in autism to the MNS, and cannot rule out the contribution of other mechanisms. In particular, differences in the perceptual processing between autistic and typical groups (Behrmann, Thomas, \& Humphreys, 2006; Blake, Turner, Smoski, Pozdol, \& Stone, 2003) have seldom been excluded. Thus, EEG and MEG studies cannot provide conclusive evidence for MNS dysfunction in autism.
fMRI studies provide a more precise localisation of abnormal brain function, though even these cannot show if a deficit is primary or secondary to autism. Most studies of goal understanding in typical adults have used fMRI, and this method can robustly localise effects to the MNS. An fMRI study of imitation in autism (Williams et al., 2006) used a non-goal-directed fingermovement imitation task (Iacoboni et al., 1999) which was first used to demonstrate the role of the MNS in imitation. However, the original finding of inferior frontal gyrus activation during imitation in typical adults was not replicated, and differences between the ASD and control groups were reported in regions outside the MNS such as the temporo-parietal junction (Williams et al., 2006). Thus, it is hard to draw clear conclusions.

The most well-known data supporting the broken mirror theory is an fMRI study which compared brain responses when children with and without autism imitated emotional facial expressions (Dapretto et al., 2006). Reduced activation was reported in the inferior frontal component of the MNS. However, imitation of emotional faces is not a goal-directed task, and is very different from the hand-grasping-object tasks which were originally used to study the MNS in monkeys (Gallese et al., 1996). Thus, the results of this study do not provide evidence for abnormal goal understanding in autism. Finally, a recent study directly testing activation of the mirror neuron system during performance of hand actions and observation of hand actions did not find any group differences between participants with and without ASD (Dinstein, Thomas, Humphreys et al., 2008). While preliminary, this data is compatible with the idea that individuals with autism do not have MNS dysfunction or goal-understanding problems.

Overall, neuroimaging evidence does not yet provide a clear answer to the question of goal understanding in autism, and this is an area where further research will be vital. In particular, only neuroimaging studies can determine if participants with autism are using mirror neuron brain regions, mentalising brain regions or maybe some other brain system altogether to succeed on a task.

\section{Understanding of one's own goals}

It is also helpful to know if processing of one's own goal-directed actions is unusual in people with autism. A few studies have tested if individuals with autism have difficulty recalling and processing their own goals, and the results are not all consistent. A study by Philips and colleagues examined whether autistic children could recognise when the outcome of their own action was caused intentionally or not (Phillips, Baron-Cohen, \& Rutter, 1998). They found that children with autism were more likely than typical children to say they did mean to hit an unintended target. While this result suggests a difficulty in monitoring and remembering one's own intentions in autism, a second study found no differences between autistic and control groups on the same task (Russell \& Hill, 2001). It is not clear if heterogeneity in the 
autistic population or some other difference explains these contradictory findings.

Further experiments in the same series found no autistic impairment in detecting which moving object on the computer screen was controlled by the child (Russell \& Hill, 2001). A recent study confirms the intactness of agency judgements (did I control the object?) in adults with autism (David et al., 2008), and shows a dissociation between good agency judgements and poor mentalising. Similarly, there is evidence that autistic children monitor and remember intended events because they complain when given a reward they did not want (Tan \& Harris, 1991). Autistic children also talk about desires just as often as children with other learning difficulties (Tager-Flusberg, 1992), but they talk less about beliefs. These data complement the studies of understanding other's goals, and add weight to the argument for normal goal processing in autism.

\section{Summary}

To summarise, a variety of studies have tested the ability to understand or imitate the basic goals and outcomes of other people's actions in autism. While results are not all consistent, the majority of these studies found no evidence of impairment, with even the studies that test goal understanding directly finding good performance. This suggests that the ability to understand and to imitate other people's simple, conventional goals is intact in individuals with autism. This is in contrast to their poor performance in other social tasks such as imitation of action style (Hobson \& Lee, 1999) or false-belief tasks (Baron-Cohen et al., 1985; Happé, 1995). This conclusion may have some interesting theoretical implications which I explore in the next section.

\section{Theories of goals and of autism}

This final section examines the mechanisms that children with autism might be using to succeed in imitation tasks, and what this might mean for the broken mirror theory and for the mentalising theory. There are two major theories describing the cognitive processes which typical individuals might use to comprehend other people's goal-directed actions. They could simulate the observed action in their mirror neuron system (Gallese \& Goldman, 1998), or they could use an inferential actionunderstanding process (Csibra, 2007) in other brain regions (Brass et al., 2007). Exploring these cognitive systems in autism is, by necessity, speculative because the precise mechanisms of action understanding in typical and autistic individuals are not yet known. However, by considering the different possibilities and the theoretical implications of each, it may be possible to design better experiments in future to test these hypotheses.

\section{The broken mirror theory}

The majority of the studies reviewed above tested whether individuals with autism have trouble understand- ing simple or familiar goal-directed actions, and difficulties were seldom reported. There is extensive evidence that simple or familiar goal-directed actions are represented in the mirror neuron system. When mirror neurons were first identified in monkeys, it was observed that they responded only to goal-directed actions (di Pellegrino et al., 1992; Gallese et al., 1996; Umilta et al., 2001). The human mirror neuron regions are more flexible and can respond to meaningless actions, but show stronger responses to familiar (CalvoMerino, Glaser, Grezes, Passingham, \& Haggard, 2005; Cross, Hamilton, \& Grafton, 2006) and goal-directed (Hamilton \& Grafton, 2006; Koski et al., 2002) actions. Patients with apraxia, who have damage to mirror neuron regions, have difficulty imitating and comprehending familiar, goal-directed actions (Buxbaum et al., 2005). Thus, there is clear evidence that mirror neuron regions have a role in comprehending simple, goal-directed actions, but as reviewed above, participants with autism succeed in simple goal imitation tasks and goal-understanding tasks. Thus, it is implausible to suggest that a broken mirror neuron system can account for social disability in autism (Arbib, 2007; Dinstein, Thomas, Behrmann, and Heeger, 2008; Hamilton, 2008; Southgate \& Hamilton, 2008).

It might be possible to reinterpret the broken mirror theory by arguing that this theory applies to the mirroring of emotions and of actions without goals (Hamilton, 2008). This idea is congruent with many recent studies which expand the scope of the MNS beyond goal-directed actions and which suggest that may different brain systems may have mirroring properties. For example, overlapping neural activations for self-related and other-related processes have been reported for emotions such as disgust (Wicker et al., 2003) and pain (Singer et al., 2004). It is possible that this emotional mirroring or mimicry is abnormal in autism, while the ability to understand and imitate goal-directed actions remains intact. While this approach might be appealing, it would dramatically reduce the theoretical strength of the broken mirror hypothesis. The broken mirror theory of autism is premised on the idea that the disruption of basic mirroring mechanisms in autism would have a cascading impact on more complex types of simulation, first goal understanding and later language and mentalising (Iacoboni \& Dapretto, 2006; Oberman \& Ramachandran, 2007; Williams et al., 2001). If goal understanding is intact in autism, as demonstrated above, then there is no clear reason for the broken mirror theory to predict abnormalities in understanding intentions and desires, or in language and mentalising.

\section{The mentalising theory}

There are clear theoretical reasons to link goal understanding to mentalising, and to consider goals as simple mental states. In the action hierarchy (Figure 1), there is no clear division between goals, intentions and desires. Furthermore, many theory papers allow a broad definition of mentalising, suggesting that goals, intentions, beliefs, desires and even perceptions and 
emotions may be considered mental states (Frith et al., 1991; Premack \& Woodruff, 1978; Saxe et al., 2004). There is also now neuroimaging evidence which links action understanding to mentalising. In particular, the inferential model of action understanding suggests that we understand actions by a process of emulation or reconstruction based on the visual input (Csibra, 2007). Recent data suggests that inferential action understanding, at least for actions which are unusual or do not have a clear purpose, engages the posterior superior temporal sulcus and temporoparietal junction (Brass et al., 2007; de Lange et al., 2008; Pelphrey, Morris, \& McCarthy, 2004). These are brain regions which are strongly associated with mentalising (Frith \& Frith, 2003) and are necessary for belief inferences (Samson, Apperly, Chiavarino, \& Humphreys, 2004). Thus, inferential goal understanding may be a mentalising process.

The data reviewed above on goal understanding in autism does not test for inferential understanding of unusual actions in detail. However, there are hints that children with autism may go beyond understanding just the familiar actions with simple goals which are represented in the MNS. In particular, success in imitation of novel, incomplete actions (Aldridge et al., 2000; Carpenter et al., 2001) suggest that children with autism may be able to make more advanced inferences about other people's intentions from watching their actions. That is, children with autism may be succeeding at a basic form of goal-mentalising. This conclusion has interesting implications for the mentalising hypothesis (Frith et al., 1991).

In particular, it suggests that a broad mentalising hypothesis is not tenable, and that it is important to consider different types of mentalising separately. Belief-mentalising impairment in autism is well documented (Baron-Cohen et al., 1985; Happé, 1995), but impairments in understanding other people's desires, perceptions, emotions, intentions or goals is less well studied. However, there are intriguing hints that, while children with autism can follow another person's line of sight (Baron-Cohen, 1989; Hobson, 1984), they have difficulty considering how another person's viewpoint differs from their own (Hamilton \& Frith, 2008). Data on emotion mentalising also suggests a distinction between intact recognition of basic emotions (Ozonoff, Pennington, \& Rogers, 1990) and impaired mentalising about more complex, social emotions (Capps, Yirmiya, \& Sigman, 1992). Further studies of emotion mentalising in autism are reviewed by Blair (2005).

These studies imply that neither perceptionmentalising nor emotion-mentalising should be considered as single processes which are globally impaired in autism. Similarly, the studies reviewed above on goal, intention and desire inference show that individuals with autism can infer other's goals, intentions and maybe also desires. This means that there cannot be a single broad mentalising process which is globally impaired in autism. Rather, there may be several different processes which contribute to our ability to understand and predict other people's behaviour based on their mental states (Baron-Cohen, 1995; Leslie, 1994). Delineating which of these processes are impaired or intact in autism and how they relate to one another is an important area for future research.

\section{Future directions}

The experimental data reviewed here reveals that individuals with autism show surprisingly good understanding of and imitation of action goals, despite their poor abilities to imitate non-goal-directed actions or to understand beliefs. This conclusion directly contradicts the predictions of the broken mirror theory of autism, which requires that goal understanding should be poor in autism. It also argues against a single broad mentalising process.

The present paper also highlights how many gaps remain in our knowledge of goals and intentions. The cognitive and neural mechanisms which support action understanding in the typical brain are only just beginning to be understood, and their development remains mysterious. More precise computational accounts may be valuable here (Oztop et al., 2006). Further studies are needed to discriminate precisely between goals, intentions, outcomes and desires, and to test understanding (not just imitation) of these different internal states in both typically developing children and those with autism. The results of such studies will have important theoretical implications for our understanding of autism and of social cognition. Neither a low-level theory (the broken mirror theory) nor a high-level theory (the broad mentalising theory) can fully account for the current data. It is likely that future theories will need to be more subtle and to distinguish between different types of mirror neuron system and different types of mentalising. Thus, blanket statements about deficits in 'the mirror neuron system' or 'mentalising' in autism will no longer be sufficient. Instead there is now scope for a better formulation of current theories and better empirical data to revolutionise our understanding of mental states in cognition.

\section{Acknowledgements}

This work is funded by grants from Autism Speaks and the ESRC to Antonia Hamilton. Thanks to Uta Frith and Dana Samson for helpful comments on the manuscript.

\section{Correspondence to}

Antonia F. de C. Hamilton, School of Psychology, University of Nottingham, University Park, Nottingham NG7 2RD, UK; Tel: +44 0115846 7921; Email: antonia. hamilton@nottingham.ac.uk 


\section{Key points}

- Children with autism are able to understand and imitate other people's goal-directed actions.

- The 'broken mirror' theory of autism cannot explain this data, and thus dysfunction of the mirror neuron system is unlikely to be a satisfactory explanation for poor social cognition in autism.

- These results may also help us refine our theories of mentalising, but further studies of different types of mentalising and of more abstract goal understanding in autism are needed.

- Clinical approaches to autism could build on children's good understanding of basic action goals to teach other social skills.

\section{References}

Aldridge, M.A., Stone, K.R., Sweeney, M.H., \& Bower, T.G.R. (2000). Preverbal children with autism understand the intentions of others. Developmental Science, 3, 294.

Arbib, M.A. (2007). Autism - more than the mirror system. Clinical Neuropsychiatry, 4, 208-222.

Avikainen, S., Kulomaki, T., \& Hari, R. (1999). Normal movement reading in Asperger subjects. Neuroreport, 10, 3467-3470.

Avikainen, S., Wohlschlager, A., Liuhanen, S., Hanninen, R., \& Hari, R. (2003). Impaired mirror-image imitation in Asperger and high-functioning autistic subjects. Current Biology, 13, 339-341.

Baron-Cohen, S. (1989). Perceptual role-taking and protodeclarative pointing in autism. British Journal of Developmental Psychology, 7, 113-127.

Baron-Cohen, S. (1995). Mindblindness: An essay on autism and theory of mind. Cambridge, MA: MIT Press.

Baron-Cohen, S., Leslie, A.M., \& Frith, U. (1985). Does the autistic child have a 'theory of mind'? Cognition, 21, 3746.

Baron-Cohen, S., Leslie, A.M., \& Frith, U. (1986). Mechanical, behavioural and intentional understanding of picture stories in autistic children. British Journal of Developmental Psychology, 4, 113-125.

Beadle-Brown, J.D. (2004). Elicited imitation in children and adults with autism: The effect of different types of actions. Journal of Applied Research in Intellectual Disabilities, 17, 37-47.

Beadle-Brown, J.D., \& Whiten, A. (2004). Elicited imitation in children and adults with autism: Is there a deficit? Journal of Intellectual and Developmental Disability, 29, 147-163.

Becchio, C., Pierno, A., Mari, M., Lusher, D., \& Castiello, U. (2007). Motor contagion from gaze: The case of autism. Brain, 130(Pt 9), 2401-2411.

Behrmann, M., Thomas, C., \& Humphreys, K. (2006). Seeing it differently: Visual processing in autism. Trends in Cognitive Science, 10, 258-264.

Bekkering, H., Wohlschlager, A., \& Gattis, M. (2000). Imitation of gestures in children is goal-directed. Quarterly Journal of Experimental Psychology A, 53, 153-164.

Bernier, R., Dawson, G., Webb, S., \& Murias, M. (2007). EEG $\mathrm{mu}$ rhythm and imitation impairments in individuals with autism spectrum disorder. Brain and Cognition, 64, 228-237.

Bernstein, N.A. (1996). On dexterity and its development. In M.L. Latash, \& M.T. Turvey, (Eds), Dexerity and its development. Mahwah, NJ: Lawrence Erlbaum Associates.

Bird, G., Leighton, J., Press, C., \& Heyes, C. (2007). Intact automatic imitation of human and robot actions in autism spectrum disorders. Proceedings of the Royal Society: Biological Sciences, 274, 3027-3031.

Blair, R.J. (2005). Responding to the emotions of others: Dissociating forms of empathy through the study of typical and psychiatric populations. Consciousness and Cognition, 14, 698-718.

Blake, R., Turner, L.M., Smoski, M.J., Pozdol, S.L., \& Stone, W.L. (2003). Visual recognition of biological motion is impaired in children with autism. Psychological Science, 14, 151-157.

Blakemore, S.J., \& Decety, J. (2001). From the perception of action to the understanding of intention. Nature Reviews Neuroscience, 2, 561-567.

Brass, M., Schmitt, R.M., Spengler, S., \& Gergely, G. (2007). Investigating action understanding: Inferential processes versus action simulation. Current Biology, 17, 2117-2121.

Buccino, G., Vogt, S., Ritzl, A., Fink, G.R., Zilles, K., Freund, H.J., et al. (2004). Neural circuits underlying imitation learning of hand actions: An event-related fMRI study. Neuron, 42, 323-334.

Buxbaum, L.J., Kyle, K.M., \& Menon, R. (2005). On beyond mirror neurons: Internal representations subserving imitation and recognition of skilled object-related actions in humans. Brain Research. Cognitive Brain Research, 25(1), 226-239.

Calvo-Merino, B., Glaser, D.E., Grezes, J., Passingham, R.E., \& Haggard, P. (2005). Action observation and acquired motor skills: An FMRI study with expert dancers. Cerebral Cortex, 15, 1243-1249.

Capps, L., Yirmiya, N., \& Sigman, M. (1992). Understanding of simple and complex emotions in nonretarded children with autism. Journal of Child Psychology and Psychiatry, 33, 1169-1182.

Carpenter, M., Pennington, B.F., \& Rogers, S.J. (2001). Understanding of others' intentions in children with autism. Journal of Autism and Developmental Disorders, 31, 589-599.

Cattaneo, L., FabbriDestro, M., Boria, S., Pieraccini, C., Monti, A., Cossu, G., et al. (2007). Impairment of actions chains in autism and its possible role in intention understanding. Proceedings of the National Academy of Sciences U S A, 104, 17825-17830.

Charman, T., \& Baron-Cohen, S. (1994). Another look at imitation in autism. Development and Psychopathology, 6, 403-413.

Charman, T., Swettenham, J., Baron-Cohen, S., Cox, A., Baird, G., \& Drew, A. (1997). Infants with autism: An investigation of empathy, pretend play, joint attention, and imitation. Developmental Psychology, 33, 781-789.

Cross, E.S., Hamilton, A.F., \& Grafton, S.T. (2006). Building a motor simulation de novo: Observation of dance by dancers. Neuroimage, 31, 1257-1267. 
Csibra, G. (2007). Action mirroring and action understanding: An alternative account. In P. Haggard, Y. Rossetti, \& M. Kawato, (Eds), Sensorimotor foundations of higher cognition: Attention and performance, XXII (pp. 435-459). Oxford: Oxford University Press.

D'Entremont, B., \& Yazbek, A. (2006). Imitation of intentional and accidental actions by children with autism. Journal of Autism and Developmental Disorders, 37, 1665-7816.

Dapretto, M., Davies, M.S., Pfeifer, J.H., Scott, A.A., Sigman, M., Bookheimer, S.Y., et al. (2006). Understanding emotions in others: Mirror neuron dysfunction in children with autism spectrum disorders. Nature Neuroscience, 9, 28-30.

David, N., Gawronski, A., Santos, N.S., Huff, W., Lehnhardt, F.G., Newen, A., et al. (2008). Dissociation between key processes of social cognition in autism: Impaired mentalizing but intact sense of agency. Journal of Autism and Developmental Disorders, 38, 593-605.

de Lange, F.P., Spronk, M., Willems, R.M., Toni, I., \& Bekkering, H. (2008). Complementary systems for understanding action intentions. Current Biology, 18, 454-457.

Decety, J., Chaminade, T., Grezes, J., \& Meltzoff, A.N. (2002). A PET exploration of the neural mechanisms involved in reciprocal imitation. Neuroimage, 15, 265272.

DeMeyer, M.K., Alpern, G.D., Barton, S., DeMyer, W.E., Churchill, D.W., Hingtgen, J.N., et al. (1972). Imitation in autistic, early schizophrenic, and non-psychotic subnormal children. Journal of Autism and Childhood Schizophrenia, 2, 264-287.

di Pellegrino, G., Fadiga, L., Fogassi, L., Gallese, V., \& Rizzolatti, G. (1992). Understanding motor events: A neurophysiological study. Experimental Brain Research, 91, 176-180.

Dinstein, I., Thomas, C., Behrmann, M., \& Heeger, D.J. (2008a). A mirror up to nature. Current Biology, 18(1), R1318.

Dinstein, I., Thomas, C., Humphreys, K., Minshew, N., Behrmann, M., \& Heeger, D.J. (2008b). Dysfunctional mirror neurons and autism - a doubtful connection. Paper presented at the International Meeting for Autism Research

Fogassi, L., Ferrari, P.F., Gesierich, B., Rozzi, S., Chersi, F., \& Rizzolatti, G. (2005). Parietal lobe: From action organization to intention understanding. Science, 308, 662-667.

Frith, U. (2003). Autism: Explaining the enigma. Oxford: Blackwell.

Frith, U., \& Frith, C.D. (2003). Development and neurophysiology of mentalizing. Philosophical Transactions of the Royal Society of London B: Biological Sciences, 358, 459-473.

Frith, U., \& Happé, F. (1994). Autism: Beyond 'theory of mind'. Cognition, 50, 115-132.

Frith, U., Morton, J., \& Leslie, A.M. (1991). The cognitive basis of a biological disorder: Autism. Trends in Neuroscience, 14, 433-438.

Fuster, J.M. (2001). The prefrontal cortex - an update: Time is of the essence. Neuron, 30, 319-333.

Gallese, V. (2003). The manifold nature of interpersonal relations: The quest for a common mechanism. Philosophical Transactions of the Royal Society of London B: Biological Sciences, 358, 517-528.

Gallese, V., Fadiga, L., Fogassi, L., \& Rizzolatti, G. (1996). Action recognition in the premotor cortex. Brain, 119(Pt 2), 593-609.
Gallese, V., \& Goldman, A. (1998). Mirror neurons and the simulation theory of mind-reading. Trends in Cognitive Sciences, 2, 493-501.

Gallese, V., Keysers, C., \& Rizzolatti, G. (2004). A unifying view of the basis of social cognition. Trends in Cognitive Sciences, 8, 396-403.

Gattis, M., Bekkering, H., \& Wohlschlaeger, A. (2002). Goal directed imitation. In A. Meltzoff, \& W. Prinz, (Eds), The imitative mind: Development, evolution and brain bases. Cambridge: Cambridge University Press.

Gazzola, V., Rizzolatti, G., Wicker, B., \& Keysers, C. (2007). The anthropomorphic brain: The mirror neuron system responds to human and robotic actions. Neuroimage, 35, 1674-1684.

Goldman, A. (2006). Simulating minds. Oxford: Oxford University Press.

Gowen, E., Stanley, J., \& Miall, R. C. (2007). Movement interference in autism-spectrum disorder. Neuropsychologia, 46, 1060-1068.

Grafton, S.T., \& Hamilton, A.F. (2007). Evidence for a distributed hierarchy of action representation in the brain. Human Movement Science, 26, 590-616.

Hamilton, A.F. (2008). Emulation and mimicry for social interaction: A theoretical approach to imitation in autism. Quarterly Journal of Experimental Psychology, 61, 101-115.

Hamilton, A.F., Brindley, R.M., \& Frith, U. (2007). Imitation and action understanding in autistic spectrum disorders: How valid is the hypothesis of a deficit in the mirror neuron system? Neuropsychologia, 45, 18591868.

Hamilton, A.F., \& Frith, U. (2008). Visual perspective taking impairment in children with autistic spectrum disorder. Manuscript submitted for publication.

Hamilton, A.F., \& Grafton, S.T. (2006). Goal representation in human anterior intraparietal sulcus. Journal of Neuroscience, 26, 1133-1137.

Hamilton, A.F., \& Grafton, S.T. (2007). The motor hierarchy: From kinematics to goals and intentions. In P. Haggard, Y. Rosetti, \& M. Kawato, (Eds), Sensorimotor foundations of higher cognition: attention and performance, XXII. Oxford: Oxford University Press.

Happé, F.G. (1995). The role of age and verbal ability in the theory of mind task performance of subjects with autism. Child Development, 66, 843-855.

Heilman, K.M., Rothi, L.J., \& Valenstein, E. (1982). Two forms of ideomotor apraxia. Neurology, 32, 342346.

Hepburn, S.L., \& Stone, W.L. (2006). Longitudinal research on motor imitation in autism. In S.J. Rogers, \& J. Williams, (Eds), Imitation and the social mind (pp. 310328). New York: Guilford Press.

Hobson, R.P. (1984). Early childhood autism and the question of egocentrism. Journal of Autism and Developmental Disorders, 14, 85-104.

Hobson, R.P., \& Hobson, J.A. (2008). Dissociable aspects of imitation: A study in autism. Journal of Experimental Child Psychology, 101, 170-185.

Hobson, R.P., \& Lee, A. (1999). Imitation and identification in autism. Journal of Child Psychology and Psychiatry, 40, 649-659.

Hurley, S. (2008). The shared circuits model (SCM): How control, mirroring, and simulation can enable imitation, deliberation, and mind-reading. Behavior and Brain Science, 31, 1-22. discussion 22-58.

Iacoboni, M., \& Dapretto, M. (2006). The mirror neuron system and the consequences of its dysfunction. Nature Reviews Neuroscience, 7, 942-951. 
Iacoboni, M., Molnar-Szakacs, I., Gallese, V., Buccino, G., Mazziotta, J.C., \& Rizzolatti, G. (2005). Grasping the intentions of others with one's own mirror neuron system. PLoS Biology, 3, e79.

Iacoboni, M., Woods, R.P., Brass, M., Bekkering, H., Mazziotta, J.C., \& Rizzolatti, G. (1999). Cortical mechanisms of human imitation. Science, 286, 2526-2528.

Ingersoll, B., Schreibman, L., \& Tran, Q.H. (2003). Effect of sensory feedback on immediate object imitation in children with autism. Journal of Autism and Developmental Disorders, 33, 673-683.

Koechlin, E., \& Jubault, T. (2006). Broca's area and the hierarchical organization of human behavior. Neuron, 50, 963-974.

Koechlin, E., Ody, C., \& Kouneiher, F. (2003). The architecture of cognitive control in the human prefrontal cortex. Science, 302, 1181-1185.

Koski, L., Wohlschlager, A., Bekkering, H., Woods, R.P., Dubeau, M.C., Mazziotta, J.C., et al. (2002). Modulation of motor and premotor activity during imitation of targetdirected actions. Cerebral Cortex, 12(8), 847-855.

Leighton, J., Bird, G., Charman, T., \& Heyes, C. (2008). Weak imitative performance is not due to a functional 'mirroring' deficit in adults with autism spectrum disorders. Neuropsychologia, 46, 1041-1049.

Leslie, A.M. (1987). Pretense and representation: The origins of 'theory of mind'. Psychology Review, 94, 412426.

Leslie, A.M. (1994). ToMM, ToBy, and Agency: Core architecture and domain specificity. In L.A. Hirschfeld, \& S. Gelman, (Eds), Mapping the mind: Domain specificity in cognition and culture (pp. 119-148). New York: Cambridge University Press.

McDonough, L., Stahmer, A., Schreibman, L., \& Thompson, S.J. (1997). Deficits, delays, and distractions: An evaluation of symbolic play and memory in children with autism. Development and Psychopathology, 9, 1741.

McIntosh, D.N., Reichmann-Decker, A., Winkielman, P., \& Wilbarger, J.L. (2006). When the social mirror breaks: Deficits in automatic, but not voluntary, mimicry of emotional facial expressions in autism. Developmental Science, 9, 295-302.

Meltzoff, A. (1995). Understanding the intentions of others: Re-enactment of intended acts by 18-month-old children. Developmental Psychology, 31, 838-850.

Morgan, S.B., Cutrer, P.S., Coplin, J.W., \& Rodrigue, J.R. (1989). Do autistic children differ from retarded and normal children in Piagetian sensorimotor functioning? Journal of Child Psychology and Psychiatry, 30, 857864.

Mozaz, M., Garaigordobil, M., Gonzalez Rothi, L.J., Anderson, J., Crucian, G.P., \& Heilman, K.M. (2006). Posture recognition in Alzheimer's disease. Brain and Cognition, $62,241-245$.

Nishitani, N., Avikainen, S., \& Hari, R. (2004). Abnormal imitation-related cortical activation sequences in Asperger's syndrome. Annual Neurology, 55, 558-562.

Oberman, L.M., Hubbard, E.M., McCleery, J.P., Altschuler, E.L., Ramachandran, V.S., \& Pineda, J.A. (2005). EEG evidence for mirror neuron dysfunction in autism spectrum disorders. Brain Research and Cognitive Brain Research, 24, 190-198.

Oberman, L.M., \& Ramachandran, V.S. (2007). The simulating social mind: The role of the mirror neuron system and simulation in the social and communicative deficits of autism spectrum disorders. Psychological Bulletin, $133,310-327$
Ohta, M. (1987). Cognitive disorders of infantile autism: A study employing the WISC, spatial relationship conceptualization, and gesture imitations. Journal of Autism and Developmental Disorders, 17, 45-62.

Ozonoff, S., Pennington, B.F., \& Rogers, S.J. (1990). Are there emotion perception deficits in young autistic children? Journal of Child Psychology and Psychiatry, 31, 343-361.

Oztop, E., Kawato, M., \& Arbib, M. (2006). Mirror neurons and imitation: A computationally guided review. Neural Networks, 9, 254-271.

Pelphrey, K.A., Morris, J.P., \& McCarthy, G. (2004). Grasping the intentions of others: The perceived intentionality of an action influences activity in the superior temporal sulcus during social perception. Journal of Cognitive Neuroscience, 16, 1706-1716.

Peterson, C.C., Wellman, H.M., \& Liu, D. (2005). Steps in theory-of-mind development for children with deafness or autism. Child Development, 76, 502-517.

Phillips, W., Baron-Cohen, S., \& Rutter, M. (1998). Understanding intention in normal development and in autism. British Journal of Developmental Psychology, 16, 337-348.

Premack, D., \& Woodruff, G. (1978). Does the chimpanzee have a theory of mind? Behavioral and Brain Sciences, 4, 515-526.

Ramachandran, V.S., \& Oberman, L.M. (2006). Broken mirrors: A theory of autism. Scientific American, 295, 6269.

Reason, J. (1990). Human error. Cambridge: Cambridge University Press.

Rizzolatti, G., \& Arbib, M.A. (1998). Language within our grasp. Trends in Neuroscience, 21, 188-194.

Rizzolatti, G., \& Craighero, L. (2004). The Mirror-Neuron System. Annual Review of Neuroscience, 27, 169-192.

Rizzolatti, G., Fogassi, L., \& Gallese, V. (2001). Neurophysiological mechanisms underlying the understanding and imitation of action. Nature Reviews Neuroscience, 2, 661-670.

Rogers, S.J., Bennetto, L., McEvoy, R., \& Pennington, B.F. (1996). Imitation and pantomime in high-functioning adolescents with autism spectrum disorders. Child Development, 67, 2060-2073.

Rogers, S.J., Hepburn, S.L., Stackhouse, T., \& Wehner, E. (2003). Imitation performance in toddlers with autism and those with other developmental disorders. Journal of Child Psychology and Psychiatry, 44, 763-781.

Russell, J., \& Hill, E.L. (2001). Action-monitoring and intention reporting in children with autism. Journal of Child Psychology and Psychiatry, 42, 317-328.

Samson, D., Apperly, I.A., Chiavarino, C., \& Humphreys, G.W. (2004). Left temporo-parietal junction is necessary for representing someone else's belief. Nature Neuroscience, 7, 499-500.

Saxe, R., Carey, S., \& Kanwisher, N. (2004). Understanding other minds: Linking developmental psychology and functional neuroimaging. Annual Review of Psychology, $55,87-124$.

Sebanz, N., Knoblich, G., \& Prinz, W. (2003). Representing others' actions: Just like one's own? Cognition, 88, B1121.

Sebanz, N., Knoblich, G., Stumpf, L., \& Prinz, W. (2005). Far from action blind: Action representation in individuals with autism. Cognitive Neuropsychology, 22, 433454.

Shallice, T., \& Burgess, P.W. (1991). Deficits in strategy application following frontal lobe damage in man. Brain, 114(Pt 2), 727-741. 
Singer, T., Seymour, B., O’Doherty, J., Kaube, H., Dolan, R.J., \& Frith, C.D. (2004). Empathy for pain involves the affective but not sensory components of pain. Science, 303, 1157-1162.

Smith, I.M., \& Byrson, S.E. (1998). Gesture imitation in autism I: Nonsymbolic postures and sequences. Cognitive Neuropsychology, 15, 747-770.

Southgate, V., \& Hamilton, A.F. (2008). Unbroken mirrors: Challenging a theory of autism. Trends in Cognitive Science, 12, 225-229.

Stone, W.L., Lemanek, K.L., Fishel, P.T., Fernandez, M.C., $\&$ Altemeier, WA. (1990). Play and imitation skills in the diagnosis of autism in young children. Pediatrics, 86, 267-272.

Stone, W.L., Ousley, O.Y., \& Littleford, C.D. (1997). Motor imitation in young children with autism: What's the object? Journal of Abnormal Child Psychology, 25, 475485.

Tager-Flusberg, H. (1992). Autistic children's talk about psychological states: Deficits in the early acquisition of a theory of mind. Child Development, 63, 161-172.

Tan, J., \& Harris, P.L. (1991). Autistic children understand seeing and wanting. Development and Psychopathology, 3, 163-174.

Tessari, A., \& Rumiati, R.I. (2004). The strategic control of multiple routes in imitation of actions. Journal of Experimental Psychology: Human Perception and Performance, 30, 1107-1116.

Theoret, H., Halligan, E., Kobayashi, M., Fregni, F., TagerFlusberg, H., \& Pascual-Leone, A. (2005). Impaired motor facilitation during action observation in individuals with autism spectrum disorder. Current Biology, 15, R84-85.

Umilta, M.A., Kohler, E., Gallese, V., Fogassi, L., Fadiga, L., Keysers, C., et al. (2001). I know what you are doing. A neurophysiological study. Neuron, 31, 155-165.

Vivanti, G., Nadig, A., Ozonoff, S., \& Rogers, S.J. (2008). What do children with autism attend to during imitation tasks? Journal of Experimental Child Psychology, 101, 186-205.
Wellman, H.M., \& Liu, D. (2004). Scaling of theory-of-mind tasks. Child Development, 75, 523-541.

Whiten, A., Flynn, E., Brown, K., \& Lee, T. (2006). Imitation of hierarchical action structure by young children. Developmental Science, 9, 574-582.

Wicker, B., Keysers, C., Plailly, J., Royet, J.P., Gallese, V., \& Rizzolatti, G. (2003). Both of us disgusted in my insula: The common neural basis of seeing and feeling disgust. Neuron, 40, 655-664.

Williams, J.H., Waiter, G.D., Gilchrist, A., Perrett, D.I., Murray, A.D., \& Whiten, A. (2006). Neural mechanisms of imitation and 'mirror neuron' functioning in autistic spectrum disorder. Neuropsychologia, 44, 610-621.

Williams, J.H., Whiten, A., \& Singh, T. (2004). A systematic review of action imitation in autistic spectrum disorder. Journal of Autism and Developmental Disorders, 34, 285-299.

Williams, J.H., Whiten, A., Suddendorf, T., \& Perrett, D.I. (2001). Imitation, mirror neurons and autism. Neuroscience and Biobehavioral Reviews, 25, 287-295.

Wimmer, H., \& Perner, J. (1983). Beliefs about beliefs: Representation and constraining function of wrong beliefs in young children's understanding of deception. Cognition, 13, 103-128.

Wing, L., Gould, J., Yeates, S.R., \& Brierley, L.M. (1977). Symbolic play in severely mentally retarded and autistic children. Journal of Child Psychology and Psychiatry, 18, 167-178.

Wohlschlager, A., Gattis, M., \& Bekkering, H. (2003). Action generation and action perception in imitation: An instance of the ideomotor principle. Philosophical Transactions of the Royal Society of London B: Biological Sciences, 358, 501-515.

Zalla, T., Labruyere, N., \& Georgieff, N. (2006). Goaldirected action representation in autism. Journal of Autism and Developmental Disorders, 36, 527-540.

Manuscript accepted 12 February 2009 